\title{
Diversity of non-acarine arachnids of the Ophathe Game Reserve, South Africa: Testing a rapid sampling protocol
}

\begin{tabular}{|c|c|}
\hline \multicolumn{2}{|c|}{$\begin{array}{l}\text { Authors: } \\
\text { Charles R. Haddad } \\
\text { Anna S. Dippenaar- } \\
\text { Schoeman } \\
\text { 2,3 }\end{array}$} \\
\hline \multicolumn{2}{|c|}{$\begin{array}{l}\text { Affiliations: } \\
\text { }{ }^{1} \text { Department of Zoology \& } \\
\text { Entomology, University of } \\
\text { the Free State, South Africa }\end{array}$} \\
\hline \multicolumn{2}{|c|}{$\begin{array}{l}{ }^{2} \text { Biosystematics, Arac } \\
\text { ARC - Plant Protectic } \\
\text { Research Institute, } \\
\text { South Africa }\end{array}$} \\
\hline \multicolumn{2}{|c|}{$\begin{array}{l}{ }^{3} \text { Department of Zoology \& } \\
\text { Entomology, University of } \\
\text { Pretoria, South Africa }\end{array}$} \\
\hline \multicolumn{2}{|c|}{$\begin{array}{l}\text { Correspondence to: } \\
\text { Charles Haddad }\end{array}$} \\
\hline \multicolumn{2}{|c|}{$\begin{array}{l}\text { Email: } \\
\text { haddadcr@ufs.ac.za }\end{array}$} \\
\hline \multicolumn{2}{|c|}{$\begin{array}{l}\text { Postal address: } \\
\text { PO Box 339, Bloemfo } \\
\text { 9300, South Africa }\end{array}$} \\
\hline \multicolumn{2}{|c|}{$\begin{array}{l}\text { Dates: } \\
\text { Received: } 09 \text { Sept. } 2014 \\
\text { Accepted: } 26 \text { May } 2015 \\
\text { Published: } 30 \text { July } 2015\end{array}$} \\
\hline \multicolumn{2}{|c|}{$\begin{array}{l}\text { How to cite this article: } \\
\text { Haddad, C.R. \& Dippenaar- } \\
\text { Schoeman, A.S., 2015, } \\
\text { 'Diversity of non-acarine } \\
\text { arachnids of the Ophathe } \\
\text { Game Reserve, South Africa: } \\
\text { Testing a rapid sampling } \\
\text { protocol', Koedoe 57(1), Art. } \\
\text { \#1255, } 15 \text { pages. http:// } \\
\text { dx.doi.org/10.4102/koedoe. } \\
\text { v57i1.1255 }\end{array}$} \\
\hline \multicolumn{2}{|c|}{$\begin{array}{l}\text { Copyright: } \\
\text { (C) 2015. The Authors. } \\
\text { Licensee: AOSIS } \\
\text { OpenJournals. This work is } \\
\text { licensed under the Creative } \\
\text { Commons Attribution } \\
\text { License. }\end{array}$} \\
\hline \multicolumn{2}{|l|}{ Read online: } \\
\hline 回呫回 & $\begin{array}{l}\text { Scan this QR } \\
\text { code with your } \\
\text { smart phone or } \\
\text { mobile device } \\
\text { to read online. }\end{array}$ \\
\hline
\end{tabular}

As part of the second phase of the South African National Survey of Arachnida (SANSA), field surveys were conducted in many degree-square grids throughout the country using a standardised rapid sampling protocol. This study reports on the arachnid diversity of the Ophathe Game Reserve (OGR) in northern KwaZulu-Natal, as found during a preliminary survey in June 2007 (mid winter) and a SANSA field survey in October 2008 (mid spring) in four representative habitats. The SANSA survey included seven sampling methods: pitfalls, beating, sweep-netting, litter sifting, hand collecting, night collecting and Winkler traps. A total of 282 species in six arachnid orders were collected during the two surveys, of which spiders were the most species-rich order (268 species in 47 families). The SANSA survey yielded 966 adult arachnids, representing six orders and 197 species, with a further 67 species represented only by immatures. Although adult arachnid abundance $(n)$ differed considerably between the four habitats (range: $156-321)$, adult species richness $\left(S_{\text {obs }}\right)$ was less variable (range: $65-85$ ). These survey results are comparable with several longer-term surveys in the Savanna biome, and indicate that the SANSA sampling protocol can yield an impressive diversity of arachnids during a relatively short period of sampling, with a high level of coverage ( $>0.8$ for sites and most sampling methods) and moderate levels of sample completion for adults (>0.55 for all sites), despite logistical and temporal challenges. Additional repetitions of the SANSA sampling protocol in other seasons will likely increase biodiversity knowledge of arachnids in OGR considerably.

Conservation implications: The implementation of rapid sampling protocols in an atlas project is essential to generate a large volume of species-level data. The SANSA protocol is an efficient means for rapidly generating arachnid data, and in future will allow for an assessment of diversity patterns in degree-square grids across South Africa.

\section{Introduction}

During recent decades, considerable efforts have been made globally to investigate and understand patterns of arthropod biodiversity, the ecological factors shaping these patterns, and the link between biodiversity loss and its effects on ecosystem functioning (Srivastava 2002). Historically, the role of arthropods in conservation and ecosystem management has been poorly studied, despite the critical functions they fulfil in ecosystems, the significant contribution they make to human survival through ecosystem services, and their considerable potential to indicate environmental changes (Kim 1993; Kremen et al. 1993). A capacity to understand ecological patterns and conservation goals benefits from the use of finer-scale taxonomic resolutions, particularly when taxonomic resources are available to generate species-level identifications (Timms et al. 2013). However, the current 'taxonomic decline' is putting increasing pressure on available human resources to deliver viable species-level data to address the aforementioned concerns, particularly for conservation and resource management (Kim \& Byrne 2006).

Atlas projects represent a mechanism through which a considerable amount of species-level biodiversity data can be generated within a reasonable amount of time. Robertson, Cumming and Erasmus (2010) defined atlas projects as collections or syntheses of original, spatially explicit data on species occurrences. According to Robertson et al. (2010), the usefulness of atlas data to endusers depends on several factors: (1) there should be a good measure of sampling effort, (2) the resolution of collected data should be fine enough to link the data to habitat variables of potential interest, (3) a sufficiently large sample size should be provided to work within a multivariate context and (4) the data should offer clear, quantitative indications of the quality of each record to provide end-users with high-quality data. 
In recent decades, several atlas projects have been implemented in South Africa to address animal biodiversity and conservation concerns, of which those on butterflies (Henning, Terblanche \& Ball 2009; Mecenero et al. 2013), reptiles (Bates et al. 2014) and the ongoing project on birds are just three prominent examples. A fourth atlas project, the South African National Survey of Arachnida (SANSA), was initiated in 1997 to investigate arachnid biodiversity in South Africa (Dippenaar-Schoeman et al. 2013). The first phase of SANSA, which lasted from 1997 to 2006, focused on coordinating research and collating all available data on these arthropods. Subsequently, the second phase (hereafter referred to as SANSA II) was initiated to, amongst other goals, identify priority areas for sampling arachnid biodiversity; that is, geographical areas that are severely underrepresented in collections. To recognise such areas, a gap analysis was performed based on approximately 50000 published and unpublished records from taxonomic and ecological literature (Foord, Dippenaar-Schoeman \& Haddad 2011a).

One of the main aims of SANSA II was to collect samples from these areas using a standardised sampling protocol to generate material that could improve the resolution of species' distribution data from the country and also be used for taxonomic studies. Identified records were included in the first atlas of South African spiders (Dippenaar-Schoeman et al. 2010), compiled to assemble georeferenced data on all described spider species in South Africa. This included information on their occurrence in the different floral biomes, agro-ecosystems and protected areas, their distribution (on a scale from locally endemic to cosmopolitan), and preliminary conservation assessment based on a rarity index (abundance) and an endemicity index (distribution). Subsequent records will be included in a forthcoming updated national species list (Dippenaar-Schoeman et al. in prep.).

Two factors were important considerations in the execution of fieldwork for SANSA II. First, human resources (i.e. practising researchers and support staff such as students and volunteers) are concentrated in the central and northeastern parts of the country, which would likely impact on the geographical coverage of sites for sampling. Using volunteers for biodiversity surveys may produce similar results to those generated by specialist researchers for some sampling methods and is beneficial with regard to the volume of work that can be completed (Lovell et al. 2009). Second, the sampling protocol developed for SANSA II requires sampling to be carried out within a short period with a small team of workers, yet employs a variety of sampling methods targeting various habitat strata to optimise the number of species generated. Although standardised and optimised sampling protocols and ad hoc sampling have different benefits in generating species data (Cardoso et al. 2009a), SANSA researchers decided on using a standardised protocol to allow for better comparison with the species richness of degree-square grids sampled in the country, thereby facilitating a better understanding of biogeographical patterns and biodiversity hotspots in the country.
During 2006, members of the South African arachnological community developed a sampling protocol for use during the SANSA II field surveys. The protocol initially proposed was that of Coddington, Griswold and Davila (1991), which has been used in arthropod surveys in a wide variety of habitats globally (e.g. Cardoso et al. 2008a, 2008b, 2009b; Coddington, Young \& Coyle 1996; Coscaron et al. 2009; Scharff et al. 2003; Sørensen, Coddington \& Scharff 2002). This protocol has often been used in forest habitats, but has rarely been tested in the diversified floral biomes of South Africa (only once in savanna; see Muelelwa et al. 2010), where the habitat structure often differs considerably from that of forests. Consequently, a standardised protocol was developed specifically for the SANSA project. This protocol could be used despite the differences in vegetation structure in the various floral biomes and was suitable for sampling most of the habitat strata with a suite of easy-to-execute methods that required minimal training of fieldworkers. The survey teams were ideally to comprise four individuals to share the sampling effort.

The fieldwork resulted in 30 degree-square grids being sampled, with a further 10 degree-squares sampled as part of student projects and volunteer sampling, thereby providing a mass of material that has vastly improved the resolution of species distribution data and provided comparable data to better understand patterns of species diversity and endemism in the country (Dippenaar-Schoeman et al. 2010). In South Africa, the Savanna biome is the best-sampled vegetation type, with the highest number of recorded species to date (Foord et al. 2011a; Foord, Dippenaar-Schoeman \& Haddad 2011b), and also features the localities with the highest spider species richness in the country (e.g. Dippenaar et al. 2008; Foord et al. 2008; Haddad, Dippenaar-Schoeman \& Wesołowska 2006; Haddad et al. 2010; Muelelwa et al. 2010; Whitmore et al. 2001).

The current study presents the results of the SANSA sampling in the Ophathe Game Reserve (OGR) in northern KwaZulu-Natal, one of only two sites sampled in the province using the standardised protocol during SANSA II, but one of 16 degree-squares sampled in the Savanna biome. In addition, we assessed the species richness and abundance of arachnids sampled with different methods, as well as sample completion and coverage for methods and habitats, to provide an indication of the efficacy of this protocol in generating arachnid biodiversity data. The results presented here will allow comparison with other sites sampled in the Savanna biome, as well as those sampled elsewhere using this protocol.

\section{Research method and design Study area and period}

The study was carried out in the OGR in the Ulundi and Mthonjaneni municipalities in northern KwaZulu-Natal, where it forms part of the eMakhosini Ophathe Heritage Park (Figure 1). The reserve (approximately 8710 ha) was 


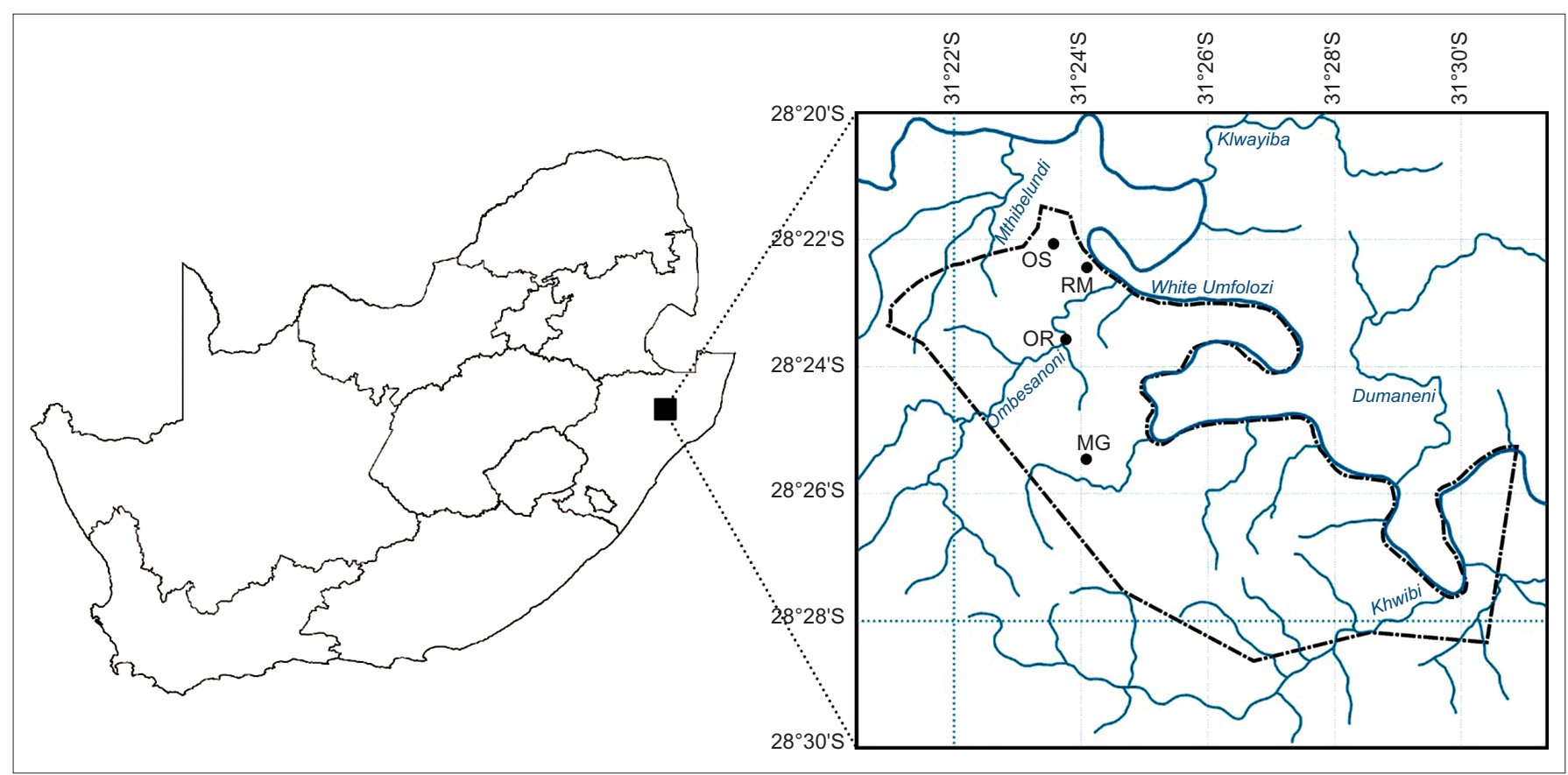

MG, montane grassland; OR, Ombesanoni River bed; OS, overgrazed savanna; RM, rocky mountainside.

FIGURE 1: Map of South Africa, showing the locality of the Ophathe Game Reserve in KwaZulu-Natal. Enlargement shows the borders of the reserve and main river systems in the area, as well as the sites sampled in the four habitats selected for the SANSA field surveys.

established only in 1991 and comprises rolling mountains largely dominated by typical Zululand Lowveld vegetation (Mthonjaneni Municipality 2013). The reserve borders the White Umfolozi River to the north, with a series of smaller tributaries passing through the reserve and entering this main regional river (Figure 1). The OGR forms part of the northern Interior ecological corridor, which borders with the OphatheImfolozi Link ecological corridor along the north-eastern border of the reserve (Mthonjaneni Municipality 2013).

Arachnids were initially collected during a 2-day visit in July 2007 (mid winter), during which time the first author was able to familiarise himself with the habitat diversity and outlay of the reserve and conduct some preliminary sampling with students. During the sampling, 59 arachnid species were collected (Appendix 1). Collection according to the SANSA standardised sampling protocol (SSP) was carried out in October 2008 (mid spring), during a period of extended drought in northern KwaZulu-Natal. Consequently, the vegetation was in a generally poor condition in all the habitats sampled, which influenced the ability of the sampling team to follow the SANSA SSP exactly.

The SANSA SSP requires the fieldwork manager to identify all the habitat types in the degree-square grid being sampled and select four that are considered representative of the area under study. The senior author selected the following four habitats in the OGR, representative of the savanna in northern KwaZulu-Natal:

- montane grassland, consisting of open grassland with a rich diversity of grasses; woody plants, including Coddia rudis, Ehretia rigida, Euclea spp., Protea caffra and
Vangueria infausta, were widely scattered and largely restricted to areas around rocky outcrops (Figure 2a)

- overgrazed savanna, dominated by Vachellia gerrardii and Albizia trees, with scattered Ziziphus mucronata, Sclerocarya birrea and Euclea spp., with a sandy substrate, sparsely scattered rocks and logs, and a virtual absence of grasses and herbs due to overgrazing and drought (Figure 2b)

- riparian vegetation along the Ombesanoni River, which runs in a northerly direction before entering the White Umfolozi River; the bed of the stream was dry at the time of the study, which exposed rocks, the gravel substrate and semi-aquatic vegetation, including grasses and restios (Figure 2c); the banks of the river were lined by a variety of trees, predominantly Vachellia and Senegalia spp., but also included Ficus and short shrubs

- a rocky mountainside, dominated by Senegalia and Vachellia trees and Euclea, Pavetta and Dichrostachys cinerea shrubs, and scattered Ziziphus mucronata trees and Aloe marlothii, with a sandy gravel substrate and a high density of rocks (Figure 2d); the grass and herb layer was severely degraded and presumably overgrazed.

\section{Sampling protocol}

As required by the SANSA SSP, the following five methods were used in each of the selected habitats:

- Fifty pitfalls, $2 \mathrm{~m}$ apart, were set out in a straight line transect. Yellow buckets with a diameter of $10 \mathrm{~cm}$ were used as the traps, with $50 \mathrm{~mL}$ of preservative (propylene glycol) added to each trap. The traps were kept open for 4 successive days before the captured material was 

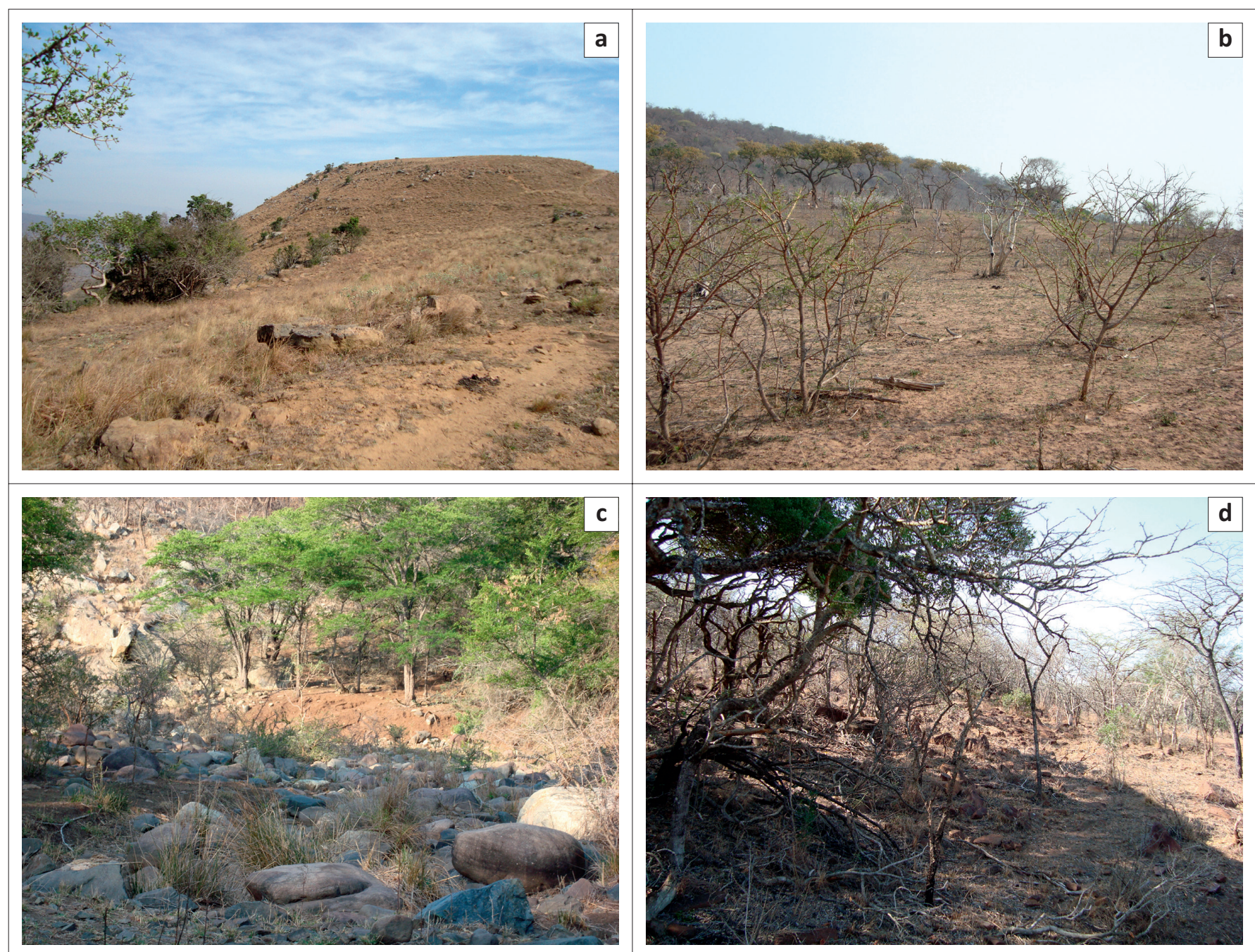

Source: Charles Haddad

FIGURE 2: Habitats sampled in the Ophathe Game Reserve during October 2008 as part of the SANSA II field survey: (a) montane grassland; (b) overgrazed savanna; (c) Ombesanoni River bed and (d) rocky mountainside.

passed through a sieve to remove excess sand, and then preserved in $70 \%$ ethanol.

- Ten samples of leaf litter were taken from beneath randomly selected trees and shrubs and sifted over a white sheet. A round sieve ( $45 \mathrm{~cm}$ in diameter and $10 \mathrm{~cm}$ high) with a mesh spacing of $8 \mathrm{~mm}$ was filled with litter for sifting; thus, samples were standardised by litter volume. All arachnids that were detected in the sheet were sampled with a glass vial and preserved in $70 \%$ ethanol.

- A total of 500 beats of tree and shrub foliage were taken at intervals of 50 beats in each habitat. Sampled material was preserved in large plastic bags before being sorted in a white tray at the field laboratory, followed by preservation in $70 \%$ ethanol.

- A total of 500 sweeps of grasses, herbs and low bushes were taken at intervals of 50 sweeps in each habitat. Sampled material was treated as described for tree and shrub foliage.

- Each team member carried out 2 hours' hand collecting in each habitat. Arachnids were collected from under rocks, logs and bark during daylight hours. (As the survey team consisted of only a single individual [senior author], only
2 hours of hand collecting was undertaken per habitat, as opposed to 8 hours that would have been undertaken with a survey team of four persons - also see night collecting described later.)

In addition to these methods, two other methods were used in the overgrazed savanna habitat:

- The fieldwork manager performed hand collecting during the night for 4 hours with the use of a headlamp. As each team member would usually collect for 2 hours, the sampling effort here represents that of 2 individuals. Specimens were collected from the soil surface, webs, bark and the foliage of plants. Night collecting was included in the protocol as the species that are nocturnally active often differ considerably from diurnal species, particularly with regard to web-building and foliagedwelling species. This method was used only in a single habitat owing to safety concerns whilst working in nature reserves (e.g. encountering potentially dangerous wild animals).

- Furthermore, four Winkler traps were filled with leaf litter from representative trees in this habitat and hung 
from the lower branches of a tree. The traps were fitted with a fine mesh sieve that allowed arthropods to fall through for collection in a bottle containing $70 \%$ ethanol.

The SANSA SSP further states that if a particular method cannot be used (e.g. owing to lack of suitable vegetation), an additional sample set of a comparable sampling method needs to be taken. In this study, the grass and herb layer in two habitats (overgrazed savanna and rocky mountainside) was so severely degraded that sweep-netting was not possible; an additional set of beating samples was therefore taken in each of these habitats (Table 1).

All of the sampled material was sorted to morphospecies in the laboratory and stored in vials filled with $70 \%$ ethanol. The first author performed preliminary identifications, which were confirmed or improved on by the second author. All the material has been deposited in the National Collection of Arachnida (NCA) at the ARC-Plant Protection Research Institute in Pretoria, South Africa.

\section{Statistical analysis}

For the purposes of statistical analysis, immature spiders were not tallied, although such morphospecies sampled were identified and recorded. However, if both adults and immatures of a species were collected together, they were included in the depositories of specimens in the NCA. In the calculations of estimated species richness and sample completeness, which rely on values of singletons and doubletons, immatures were scored a default value of 3 to avoid their contributing to these values. Estimated richness and completeness were calculated for two data sets, one including and the other excluding juveniles in addition to adults. Coverage was calculated based only on adult data, as abundance is a component of the calculation and juveniles were not all tallied.

Estimated species richness was calculated using the equation $S_{\text {chaol }}=S_{\text {obs }}+F_{1}^{2} / 2 F_{2}$, where $F_{1}$ equals the number of observed species $\left(S_{\text {obs }}\right)$ represented by one individual (singletons) and $F_{2}$ equals the number of observed species represented by two individuals (doubletons) (Magurran 2004). Chao1 is based on the available abundance data and is a function of the ratio between the singletons and doubletons in the data. With increasing samples, the curve reaches an asymptote when each species in the community is represented by at least two individuals. Following Sørensen et al. (2002), Scharff et al. (2003) and Cardoso et al. (2008b), sampling completeness was calculated as the ratio of the observed species richness and Chao1-estimated species richness.

Chao and Jost (2012) proposed the use of coverage-based rarefaction and extrapolation in assessing community richness and sampling effort. They define sample coverage as the proportion of the total number of individuals in a community that belong to the species represented in the sample. Subtracting the sample coverage from unity gives the proportion of the community belonging to unsampled species, which they refer to as the 'coverage deficit'. The coverage deficit of the sample can also be explained as the probability that a new, previously unsampled species will be found if the sample were increased by one individual (Chao \& Jost 2012). The following equation was used to calculate coverage for habitats and sampling methods in separate analyses:

$$
\hat{\mathrm{C}} n=1-\frac{f_{1}}{n}\left[\frac{(n-1) f_{1}}{(n-1) f_{1}+2 f_{2}}\right]
$$

where $n$ is the number of adult individuals in the sample, $f_{1}$ the number of singletons and $f_{2}$ the number of doubletons. Chao and Lee (1992) propose that an estimated coverage value should be at least $50 \%$.

\section{Results}

\section{Abundance and diversity}

A total of 282 arachnid species were collected during the two visits to OGR. Spiders (Araneae) were the overwhelmingly dominant order, represented by 268 species from 47 families. Of these, 966 adult arachnids, representing 197 species, were collected in 2008 using the SANSA SSP, with a further 67 morphospecies represented only by subadults or juveniles. Five other arachnid orders were also sampled: Scorpiones (five species in two families), Pseudoscorpiones (four species in four families), Opiliones (three species in two families), and Amblypygi and Solifugae (one species each). Of the species collected during the preliminary survey in 2007, 18 were not collected using the SANSA SSP the following year (Appendix 1).

In assessing the composition of the spider fauna sampled in the reserve to date, Salticidae was the most species-rich family (51 spp.), followed by Thomisidae (36 spp.), Theridiidae (32 spp.), Gnaphosidae (21 spp.) and Araneidae (18 spp.). This pattern is consistent with surveys elsewhere in the Savanna biome where multiple habitat strata have been sampled (Foord et al. 2011b).

\section{Habitat differences}

The rocky mountainside and the Ombesanoni River bed had similar overall species richness and adult species richness, which were markedly higher than in the other two habitats (Table 1). However, when Chao1-estimated species richness was calculated, the rocky mountainside had a considerably higher estimate compared with the other habitats. The largest number of adult individuals was collected from the rocky mountainside $(n=321)$, whereas the lowest number was recorded in the montane grassland $(n=156)$. The proportion of adult morphospecies to total morphospecies (including immatures) was similar between habitats, varying between $55.6 \%$ and $62.5 \%$. However, when the entire arachnid assemblage was compared across habitats, the proportion of adult morphospecies was nearly 75\% (Table 1).

Sample completeness for each habitat (Table 1) varied between $56.6 \%$ and $78.2 \%$ for adult spiders $(68.8 \%$ for 
TABLE 1: Arachnid species richness (adult morphospecies vs total morphospecies, including immatures) sampled using seven methods during the SANSA II field survey in the Ophathe Game Reserve in KwaZulu-Natal, October 2008.

\begin{tabular}{|c|c|c|c|c|c|c|}
\hline \multirow[t]{2}{*}{ Variable } & \multicolumn{4}{|c|}{ Adults versus morphospecies from different habitats } & \multirow{2}{*}{$\begin{array}{l}\text { Average (adults versus } \\
\text { morphospecies) }\end{array}$} & \multirow[t]{2}{*}{ Total } \\
\hline & MG & OR & OS & RM & & \\
\hline \multicolumn{7}{|l|}{ Sampling method } \\
\hline Active searching & $24 / 32$ & $30 / 36$ & $18 / 24$ & $23 / 37$ & $23.75 / 32.25$ & - \\
\hline Beating 1 & $11 / 35$ & $23 / 48$ & $16 / 37$ & $19 / 41$ & $17 / 40.25$ & - \\
\hline Beating 2 & - & - & $12 / 28$ & $19 / 47$ & $15.5 / 37.5$ & - \\
\hline [Beating total] & $11 / 35$ & $23 / 48$ & $21 / 57$ & $27 / 69$ & $20.5 / 52.25$ & - \\
\hline Litter sifting & $21 / 37$ & $19 / 33$ & $8 / 11$ & $15 / 29$ & $15.75 / 27.5$ & - \\
\hline Night collecting & - & - & $15 / 27$ & - & $15 / 27$ & - \\
\hline Pitfall traps & $21 / 27$ & $29 / 36$ & $26 / 33$ & $36 / 39$ & $25.5 / 33.75$ & - \\
\hline Sweeps & $3 / 7$ & $13 / 22$ & - & - & $8 / 14.5$ & - \\
\hline Winkler traps & - & - & $4 / 5$ & - & $4 / 5$ & - \\
\hline \multicolumn{7}{|l|}{ Statistical results } \\
\hline Total richness $\left(S_{\text {obs }}\right)$ & $65 / 109$ & $85 / 136$ & $68 / 118$ & $79 / 142$ & - & $197 / 264$ \\
\hline Percentage adult morphospecies & 59.6 & 62.5 & 57.6 & 55.6 & - & 74.6 \\
\hline Adult singletons $\left(F_{1}\right)$ & 29 & 30 & 23 & 33 & - & 50 \\
\hline Adult doubletons $\left(F_{2}\right)$ & 9 & 19 & 7 & 9 & - & 14 \\
\hline Adult abundance $(n)$ & 156 & 230 & 259 & 321 & - & 966 \\
\hline Chao1 richness (incl. imm.) & 156 & 160 & 156 & 203 & - & 353 \\
\hline Chao1 richness (adults) & 112 & 109 & 106 & 140 & - & 286 \\
\hline Sample completeness (\%) (incl. imm.) & 70.00 & 85.17 & 75.75 & 70.12 & - & 74.73 \\
\hline Sample completeness (\%) (adults) & 58.18 & 78.21 & 64.28 & 56.63 & - & 68.81 \\
\hline Coverage (\%) (adults) & 81.48 & 87.03 & 91.14 & 89.74 & - & 94.83 \\
\hline
\end{tabular}

imm., immatures; MG, montane grassland; OR, Ombesanoni River bed; OS, overgrazed savanna; RM, rocky mountainside.

the four sites combined), and between $70 \%$ and $85.2 \%$ for assemblages including immature morphospecies $(74.7 \%$ for combined sites). Coverage values for habitats all exceeded $80 \%$, indicating that the sampling methodology adequately sampled the representative communities of each habitat. The coverage for the entire arachnid assemblage was nearly $95 \%$, indicating that a large proportion of the regional diversity had been sampled. Indeed, when comparing the total number of morphospecies (including immatures) sampled using the SSP (264), this value is only slightly lower than the Chao1 estimate based on adult morphospecies only (286).

\section{Assessment of the South African National Survey of Arachnida standardised sampling protocol}

Active searching and pitfall traps yielded the greatest species richness of adult spiders, although beating yielded a greater number of morphospecies (including immatures) than either of the two aforementioned methods. Pitfall trapping yielded the greatest number of adult spiders per sample, followed by beating and active searching. Sweep-netting and Winkler traps were the least efficient sampling methods utilised with regard to species richness and adult abundance per sample (Table 2).

Sample completeness varied considerably between methods. When adult spiders were considered, only active searching and litter sifting gave values above $50 \%$. However, when immatures were also included in the analysis, pitfall trapping also exceeded this threshold value. The absence of sample Chao1 and sample completeness values for Winkler traps can be explained by the absence of any doubleton species in the sample, resulting in a zero value, which could not be computed. In contrast, coverage levels were
TABLE 2: Assessment of the efficacy of seven sampling methods used during the SANSA II field survey in the Ophathe Game Reserve in KwaZulu-Natal, October 2008.

\begin{tabular}{|c|c|c|c|c|c|c|c|}
\hline \multirow[t]{2}{*}{ Indicator } & \multicolumn{7}{|c|}{ Sampling method } \\
\hline & AS & BT & LS & NC & PT & SN & WT \\
\hline Number of samples & 4 & 6 & 4 & 1 & 4 & 2 & 1 \\
\hline Adult abundance $(n)$ & 177 & 318 & 158 & 26 & 272 & 21 & 4 \\
\hline $\begin{array}{l}\text { Average adults/ } \\
\text { sample }\end{array}$ & 44.25 & 53 & 39.5 & 26 & 68 & 10.5 & 4 \\
\hline Total richness $\left(S_{\text {obs }}\right)$ & 84 & 104 & 78 & 29 & 93 & 27 & 5 \\
\hline Adult richness $\left(S_{\text {obs }}\right)$ & 65 & 52 & 48 & 17 & 77 & 16 & 4 \\
\hline Adult singletons $\left(F_{1}\right)$ & 26 & 23 & 23 & 12 & 40 & 13 & 4 \\
\hline Adult doubletons $\left(F_{2}\right)$ & 14 & 2 & 11 & 2 & 10 & 1 & 0 \\
\hline $\begin{array}{l}\text { Chao } 1 \text { richness (incl. } \\
\text { imm.) }\end{array}$ & 108 & 236 & 102 & 65 & 173 & 112 & - \\
\hline $\begin{array}{l}\text { Chao1 richness } \\
\text { (adults) }\end{array}$ & 89 & 184 & 72 & 53 & 157 & 101 & - \\
\hline $\begin{array}{l}\text { Sample completeness } \\
\text { (\%) (incl. imm.) }\end{array}$ & 77.68 & 44.02 & 76.44 & 44.62 & 53.76 & 24.22 & - \\
\hline $\begin{array}{l}\text { Sample completeness } \\
\text { (\%) (adults) }\end{array}$ & 72.92 & 28.22 & 66.62 & 32.08 & 49.04 & 15.92 & - \\
\hline Coverage (\%) (adults) & 85.4 & 92.77 & 85.53 & 54.45 & 85.32 & 38.57 & 0 \\
\hline
\end{tabular}

The indicator values provided were used in calculating the sample coverage according to Chao and Jost (2012); see equation 1 for the definition of variables.

AS, active searching; BT, beating; LS, litter sifting; imm., immatures; NC, night collecting; PT, pitfall trapping; SN, sweep-netting; WT, Winkler traps.

above $50 \%$ for all of the methods except sweep-netting and Winkler traps (Table 2), suggesting that an adequately representative sample had been collected using all but these two methods.

\section{Ethical considerations}

The SANSA SSP was designed and approved during a meeting of the SANSA Steering Committee, in collaboration with members of the arachnological community and the South African National Biodiversity Institute. Collecting permits for the sampling in the OGR were provided by Ezemvelo KZN Wildlife (permit 2496/2006). 


\section{Discussion}

The current study provides the first report on the efficacy of the SANSA SSP in determining arachnid biodiversity in a savanna reserve. The results indicate that a similar diversity of arachnid species was generated during a week's sampling (264 species) as over much longer and more intensive surveys of savanna biodiversity. For example, Whitmore et al. $(2001,2002)$ collected 268 species in the Makalali Private Game Reserve in Limpopo, where five habitat types were sampled using four sampling methods (sweeping, beating, active searching and pitfalls) during four sampling periods. The number of adult species in this study (197) compares favourably with the 186 species collected in Blouberg Nature Reserve and the 222 species collected in the Western Soutpansberg Conservancy by Muelelwa et al. (2010), who used six sampling methods in four habitats each over two sampling periods. With regard to habitat and total assemblage, sample completeness and coverage values were reasonably high, indicating that a large proportion of the species pool had been sampled.

However, species richness was considerably lower than in the Ndumo Game Reserve in northern KwaZulu-Natal (457 species), where ad hoc collecting was carried out during 11 sampling periods over the course of 7 years (Haddad et al. 2006). The diversity found in that study provides some indication of the potential species richness of the OGR, as the localities are separated only by approximately $200 \mathrm{~km}$. Based on the data generated using the SSP, the Chao1estimated species richness for the OGR is 353 species, with data on immatures also considered, so it is plausible that the richer habitat diversity at Ndumo (including various forest types not occurring in the OGR) contributes greatly to its much higher arachnid diversity. As an example, nearly 90 species of Salticidae have been recorded from Ndumo Game Reserve to date (Wesołowska \& Haddad 2009, 2013; also subsequent sampling). Of the 51 species collected in the current study, approximately three quarters have also been recorded from Ndumo, whereas several others are unique to the OGR.

So far, this study has contributed material included in the descriptions of several new species of Salticidae (Wesołowska, Azarkina \& Russell-Smith 2014; Wesołowska \& Haddad 2009, 2013), Oonopidae (Platnick \& Dupérré 2010), Corinnidae (Haddad 2012, 2013a) and Thomisidae (Honiball Lewis \& Dippenaar-Schoeman 2014), as well as other taxonomic papers (Haddad 2013b, 2013c; Haddad \& Louw 2012; Haddad \& Wesołowska 2013; Jäger 2014) and molecular studies (Miller et al. 2010). This highlights the importance of the SANSA surveys in contributing towards improving taxonomic knowledge of the South African arachnid fauna, which was one of the main initial aims of this atlas project (Dippenaar-Schoeman et al. 2013).

Despite the rich diversity of arachnid species collected, it is clear that repeat surveys using the SANSA SSP during other seasons will likely yield a considerable number of additional species from the reserve, which is supported by the sample completeness values for the habitats sampled. To illustrate this, 18 of the 59 species collected during the site visit in mid winter (2007) were not collected again during the SANSA sampling in the spring of the following year (2008). Therefore, considerable assumed seasonal differences in assemblage structure in savanna habitats need to be accounted for. Unfortunately, time constraints and the shortage of human resources for the SANSA project were the greatest hindrance to repetitive sampling of sites; this can be addressed by future sampling efforts.

Furthermore, the size of each SANSA survey team clearly impacts on the biodiversity data generated. In the current study, only a single professional arachnologist was involved in the execution of the SSP (except for pitfall trapping, where assistance was provided). Consequently, methods that are quantitatively prescribed according to man-hours (e.g. hand collecting and night collecting) as opposed to a set number of samples (e.g. beats and sweeping) will be affected by the number of collectors, which, in some cases, is reflected in the sample completeness and coverage values for some methods. As most of the SANSA survey teams consist of three or four participants, it is plausible that methods based on man-hours will yield considerably more species than if only one collector was involved, as in this case. As a result, only 2 man-hours of hand collecting were conducted in each habitat in this study, as opposed to up to 8 man-hours at other localities sampled with larger teams.

It is recommended that future sampling using the SSP should take the team size into consideration and that smaller teams should spend more time per person on these methods to provide more comparable data sets. As such, methods based on man-hours should standardise efforts to equal that of four participating collectors (e.g. 8 hours for hand collecting). Although most of the sampling methods had high sample completeness $(>50 \%)$ and coverage values (> 80\%), values for night collecting, sweep-netting and Winkler traps were notably low. Although some of these values could be attributed to lower sampling effort, vegetation quality (e.g. for sweep-netting) may also have played a role. We propose that the SSP should not be amended for these methods before further data sets become available for comparison and analysis.

\section{Conclusion}

Standardised sampling protocols designed for rapid biodiversity assessments can generate large amounts of biodiversity data for atlas projects, particularly when human resources and time are limited. The current study presented the first results of the use of the SANSA protocol in a savanna reserve. Use of this protocol yielded 264 species of arachnids from the four sampled habitats. The diversity is comparable with several longer-term surveys conducted in the Savanna biome, and the protocol shows considerable potential for generating comparable data on arachnids from this biome. 


\section{Acknowledgements}

The second phase of SANSA was funded by the South African National Biodiversity Institute. Ezemvelo KZN Wildlife and the staff of the OGR are thanked for permission to collect in the reserve, collecting permits and for providing accommodation during fieldwork. Catharine Hanekom (Ezemvelo KZN Wildlife) and Samantha Haddad (University of the Free State) provided field assistance. Debbie Jewitt (Ezemvelo KZN Wildlife) provided data on the plant diversity of OGR. We are grateful to Lorenzo Prendini (American Museum of Natural History, New York) for the identification of the scorpions, Leon Lotz (National Museum, Bloemfontein) for identifying the Opiliones and Eutichuridae, Rudy Jocqué (Royal Museum for Central Africa, Tervuren) for the identification of some Zodariidae and Linyphiidae, and Jan-Andries Neethling (University of the Free State) and Mark Harvey (Western Australian Museum, Perth) for identifications of the pseudoscorpions.

\section{Competing interests}

The authors declare that they have no financial or personal relationships that may have inappropriately influenced them in writing this article.

\section{Authors' contributions}

C.R.H. (University of the Free State) is the SANSA assistant project manager. He performed the field survey, conducted preliminary identifications, performed the statistical analysis and wrote part of the manuscript. A.S.D.-S. (ARC - Plant Protection Research Institute) is the SANSA project manager. She performed identifications and wrote part of the manuscript.

\section{References}

Bates, M.F., Branch, W.R., Bauer, A.M., Burger, M., Marais, J., Alexander, G.J. et al. (eds.), 2014, Atlas and red list of the reptiles of South Africa, Lesotho and Swaziland South African National Biodiversity Institute, Pretoria (Suricata series; no. 1).

Cardoso, P., Crespo, L.C., Carvalho, R., Rufino, A.C. \& Henriques, S.S., 2009a, 'Ad-hoc vs. standardized and optimized arthropod diversity sampling', Diversity 1, 36-51. http://dx.doi.org/10.3390/d1010036

Cardoso, P., Gaspar, C., Pereira, L.C., Silva, I., Henriques, S.S., Silva, R.R. et al. 2008a, 'Assessing spider species richness and composition in Mediterranean 2008 a, 'Assessing spider species richness and composition in Mediterranean
cork oak forests', Acta Oecologia 33, 114-127. http://dx.doi.org/10.1016/j. cork oak forests',

Cardoso, P., Henriques, S.S., Gaspar, C.S., Crespo, L.C., Carvalho, R., Schmidt, J.B. et al., 2009b, 'Species richness and composition assessment of spiders in a Mediterranean scrubland', Journal of Insect Conservation 12, 45-55. http:// dx.doi.org/10.1007/s10841-007-9116-3

Cardoso, P., Scharff, N., Gaspar, C.S., Henriques, S.S., Carvalho, R., Castro, P.H. et al., 2008b, 'Rapid biodiversity assessment of spiders (Araneae) using semiquantitative sampling: A case study in a Mediterranean forest', Insect Conservation quantitative sampling: A case study in a Mediterranean forest', Insect Conservatio

Chao, A. \& Jost, L., 2012, 'Coverage-based rarefaction and extrapolation: Standardizing samples by completeness rather than size', Ecology 93, 2533-2547. http://dx.doi. org/10.1890/11-1952.1

Chao, A. \& Lee, S.M., 1992, 'Estimating the number of classes via sample coverage', Journal of the American Statistical Association 87, 210-217. http://dx.doi.org/10. 1080/01621459.1992.10475194

Coddington, J.A., Griswold, C.E. \& Davila, D.S., 1991, 'Designing and testing sampling protocols to estimate biodiversity in tropical ecosystems', in E.C. Dudley (ed.), The unity of evolutionary biology: Proceedings of the fourth international congress of systematics and evolutionary biology, pp. 44-60, Dioscorides Press, Portland.

Coddington, J.A., Young, L.H. \& Coyle, F.A., 1996, 'Estimating spider species richness in a southern Appalachian Cove Hardwood forest', Journal of Arachnology 24 111-128.

Coscaron, M.C., Melo, C., Coddington, J.A. \& Corronca, J., 2009, 'Estimating biodiversity: A case study on true bugs in Argentinian wetlands', Biodiversity and Conservation 18, 1491-1507. http://dx.doi.org/10.1007/s10531-008-9515-0
Dippenaar, S.M., Dippenaar-Schoeman, A.S., Modiba, M.A. \& Khoza, T.T., 2008, 'A checklist of spiders (Arachnida, Araneae) of the Polokwane Nature Reserve, Limpopo Province, South Africa', Koedoe 50, 10-17. http://dx.doi.org/10.4102/ kimpopo Province,

Dippenaar-Schoeman, A.S., Haddad, C.R., Foord, S.H., Lyle, R., Helberg, L., Mathebula, S. et al., 2010, First atlas of the spiders of South Africa (Arachnida: Araneae), ARC Plant Protection Research Institute, Pretoria.

Dippenaar-Schoeman, A.S., Van den Berg, A.M., Lyle, R., Haddad, C.R., Foord, S.H. \& Lotz, L.N., 2013, 'Die diversiteit van Suid-Afrikaanse spinnekoppe (Arachnida: Araneae): dokumentering van 'n nasionale opname [The diversity of South African spiders (Arachnida: Araneae): Documenting a national survey]', Tydskrif van die Suid-Afrikaanse Akademie vir Wetenskap en Kuns 32(375), 1-7.

Foord, S.H., Dippenaar-Schoeman, A.S. \& Haddad, C.R., 2011a, 'South African spider diversity: African perspectives on the conservation of a mega-diverse group', in O. Grillo \& G. Venora (eds.), Changing diversity in changing environment, pp. 163-182, InTech Publishing, Rijeka.

Foord, S.H., Dippenaar-Schoeman, A.S. \& Haddad, C.R., 2011b, 'The faunistic diversity of spiders (Arachnida, Araneae) of the Savanna Biome in South Africa' Transactions of the Royal Society of South Africa 66, 170-201. http://dx.doi.org/1 0.1080/0035919X.2011.639406

Foord, S.H., Mafadza, M., Dippenaar-Schoeman, A.S. \& Van Rensburg, B.J., 2008, 'Micro-scale heterogeneity of spiders (Arachnida: Araneae) in the Soutpansberg, South Africa: A comparative survey and inventory in representative habitats', African Zoology 43, 156-174. http://dx.doi.org/10.3377/1562-702043.2.156

Haddad, C.R., 2012, 'A revision of the Afrotropical spider genus Cambalida Simon 1909 (Araneae: Corinnidae)', ZooKeys 234, 67-119. http://dx.doi.org/10.3897/ zookeys.234.3417

Haddad, C.R., 2013a, 'Taxonomic notes on the spider genus Messapus Simon, 1898 (Araneae, Corinnidae), with the description of the new genera Copuetta and Wasaka and the first cladistic analysis of Afrotropical Castianeirinae', Zootaxa 3688, 1-79. http://dx.doi.org/10.11646/zootaxa.3688.1.1

Haddad, C.R., 2013b, 'A revision of the continental species of Copa Simon, 1885 (Araneae: Corinnidae) in the Afrotropical Region', ZooKeys 276, 1-37. http:// dx.doi.org/10.3897/zookeys.276.4233

Haddad, C.R., 2013c, 'A revision of the ant-like sac spider genus Apochinomma Pavesi, 1881 (Araneae: Corinnidae) in the Afrotropical Region', Journal of Natural History 47, 2493-2529. http://dx.doi.org/10.1080/00222933.2013.791933

Haddad, C.R., Dippenaar-Schoeman, A.S. \& Wesołowska, W., 2006, 'A checklist of the non-acarine arachnids (Chelicerata: Arachnida) of the Ndumo Game Reserve, Maputaland, South Africa', Koedoe 49, 1-22. http://dx.doi.org/10.4102/koedoe. v49i2.116

Haddad, C.R., Honiball, A.S., Dippenaar-Schoeman, A.S., Slotow, R. \& Van Rensburg, B.J., 2010, 'Spiders (Arachnida: Araneae) as indicators of elephant-induced habitat changes in the Maputaland Centre of Endemism, South Africa', African Journal of Ecology 48, 446-460. http://dx.doi.org/10.1111/j.1365-2028.2009.01133.x

Haddad, C.R. \& Louw, S.vdM., 2012, 'A redescription of Merenius alberti Lessert, 1923 (Araneae: Corinnidae), with remarks on colour polymorphism and its relationship to ant models', African Invertebrates 53, 571-591. http://dx.doi.org/10.5733/ afin.053.0213

Haddad, C.R. \& Wesołowska, W., 2013, 'Additions to the jumping spider fauna of South Africa (Araneae: Salticidae)', Genus 24, 459-501.

Henning, G.A., Terblanche, R.F. \& Ball, J.B. (eds.), 2009, South African red data book: Butterflies, SANBI Biodiversity Series 13, South African National Biodiversity Institute, Pretoria.

Honiball Lewis, A.S. \& Dippenaar-Schoeman, A.S., 2014, 'Revision of the spider genus Mystaria Simon, 1895 (Araneae: Thomisidae) and the description of a new genus from the Afrotropical region', Zootaxa 3873, 101-144. http://dx.doi. org/10.11646/zootaxa.3873.2.1

Jäger, P., 2014, 'Olios sjostedti Lessert, 1921 (Araneae: Sparassidae): First description of the female and first records from South Africa and Botswana', African Invertebrates 55, 201-208.

Kim, K.C., 1993, 'Biodiversity, conservation and inventory: Why insects matter', Biodiversity and Conservation 2, 191-214. http://dx.doi.org/10.1007/BF00056668

Kim, K.C. \& Byrne, L.B., 2006, 'Biodiversity loss and the taxonomic bottleneck: Emerging biodiversity science', Ecological Research 21, 794-810. http://dx.doi. org/10.1007/s11284-006-0035-7

Kremen, C., Colwell, R.K., Erwin, T.L., Murphy, D.D., Noss, R.F. \& Sanjayan, M.A., 1993, 'Terrestrial arthropod assemblages: Their use in conservation planning', Conservation Biology 7, 796-808. http://dx.doi.org/10.1046/j.15231739.1993.740796.x

Lovell, S., Hamer, M., Slotow, R. \& Herbert, D., 2009, 'An assessment of the use of volunteers for terrestrial invertebrate biodiversity surveys', Biodiversity and Conservation 18, 3295-3307. http://dx.doi.org/10.1007/s10531-009-9642-2

Magurran, A.E., 2004, Measuring biological diversity, Blackwell, Bodmin.

Mecenero, S., Ball, J.B., Edge, D.A., Hamer, M.L., Henning, G.A., Krüger, M.A et al. (eds.), 2013, Conservation assessment of butterflies of South Africa, Lesotho and Swaziland: Red list and atlas, Saftronics Publishing, Johannesburg and Avian Demography Unit, Cape Town.

Miller, J.A., Carmichael, A., Ramirez, M.J., Haddad, C.R., Řezáč, M., Johannesen, J. et al., 2010, 'Phylogeny of entelegyne spiders: Affinities of the family Penestomidae (NEW RANK), generic phylogeny of Eresidae, and asymmetric rates of change in spinning organ evolution (Araneae, Araneoidea, Entelegynae)' Molecular Phylogenetics and Evolution 55, 786-804. http://dx.doi.org/10.1016/j. Molecular Phylogene
ympev.2010.02.021

Mthonjaneni Municipality, 2013, 'Draft Mthonjaneni spatial development framework', unpublished report, Mthonjaneni Municipality. 
Muelelwa, M.I., Foord, S.H., Dippenaar-Schoeman, A.S. \& Stam, E.M., 2010, 'Towards a standardized and optimized protocol for rapid assessments: Spider species richness and assemblage composition in two savanna vegetation types', African richness and assemblage composition in two savanna vegetation
Zoology 45, 273-290. http://dx.doi.org/10.3377/004.045.0206

Platnick, N.I. \& Dupérré, N., 2010, 'The goblin spider genera Stenoonops and Australoonops (Araneae, Oonopidae), with notes on related taxa', Bulletin of the American Museum of Natural History 340, 1-111. http://dx.doi.org/10.1206/714.1

Robertson, M.P., Cumming, G.S. \& Erasmus, B.F.N.,Getting the most out of atlas data', Diversity and Distributions 16, 363-375. http://dx.doi.org/10.1111/j.1472 4642.2010.00639.x

Scharff, N., Coddington, J.A., Griswold, C.E., Hormiga, G. \& Bjorn, P., 2003, 'When to quit? Estimating spider species richness in a northern European deciduous forest', Journal of Arachnology 31, 246-273. http://dx.doi.org/10.1636/0161 8202(2003)031[0246:WTQESS]2.0.CO;2

Sørensen, L.I., Coddington, J.A. \& Scharff, N.J., 2002, 'Inventorying and estimating subcanopy spider diversity using semiquantitative sampling methods in an Afromontane forest', Environmental Entomology 31, 319-330. http://dx.doi. org/10.1603/0046-225X-31.2.319

Srivastava, D.S., 2002, 'The role of conservation in expanding biodiversity research' Oikos 98, 351-360. http://dx.doi.org/10.1034/j.1600-0706.2002.980216.x
Timms, L.L., Bowden, J.J., Summerville, K.S. \& Buddle, C.M., 2013, 'Does species-level resolution matter? Taxonomic sufficiency in terrestrial arthropod biodiversity studies', Insect Conservation and Diversity 6, 453-462. http://dx.doi.org/10.1111/ icad.12004

Wesołowska, W., Azarkina, G.N. \& Russell-Smith, A., 2014, 'Euophryine jumping spiders of the Afrotropical Region - new taxa and a checklist (Araneae: Salticidae: Euophryinae)', Zootaxa 3789, 1-72. http://dx.doi.org/10.11646/zootaxa. 3789.1.1

Wesołowska, W. \& Haddad, C.R., 2009, 'Jumping spiders (Araneae: Salticidae) of the Ndumo Game Reserve, Maputaland, South Africa', African Invertebrates 50 13-103. http://dx.doi.org/10.5733/afin.050.0102

Wesołowska, W. \& Haddad, C.R., 2013, 'New data on the jumping spiders of South Africa (Araneae: Salticidae)', African Invertebrates 54, 177-240.

Whitmore, C., Crouch, T.E., Slotow, R. \& Dippenaar-Schoeman, A.S., 2001, 'Checklist of spiders (Araneae) from Makalali Private Game Reserve, Northern Province, South Africa: Including a new family record', Durban Museum Novitates 26, 10-19.

Whitmore, C., Slotow, R., Crouch, T.E. \& Dippenaar-Schoeman, A.S., 2002, 'Diversity of spiders (Araneae) in a savanna reserve, Northern Province, South Africa', Journal of Arachnology 30,344-356. http://dx.doi.org/10.1636/0161 8202(2002)030[0344:DOSAIA]2.0.CO;2 


\section{Appendix 1}

APPPENDIX 1: Checklist of the arachnids of the Ophathe Game Reserve in KwaZulu-Natal, South Africa, with sampling methods in each habitat indicated.

Species
ORDER: AMBLYPYGI (TAILLESS WHIP-SCORPIONS)
PHYRNICHIDAE

\section{PHYRNICHIDAE}

Damon annulatipes (Wood, 1869)

MG

OR

os

\section{ORDER: ARANEAE (SPIDERS)}

AGELENIDAE

Benoitia sp.

\section{AMAUROBIIDAE}

Amaurobiidae sp. 1 indet. $†$

Amaurobiidae sp. 2 indet.

A

\section{ARANEIDAE}

Afracantha camerunensis (Thorell, 1899)

Argiope aurocincta Pocock, $1898 \mathrm{imm}$.

Caerostris sexcuspidata (Fabricius, 1793) imm.

Caerostris vicina (Blackwall, 1866) imm.

Chorizopes sp.

Cyphalonotus larvatus (Simon, 1881)

Cyrtophora citricola (Forsskål, 1775)

Hypsacantha crucimaculata (Dahl, 1914)

Hypsosinga sp. imm.

Isoxya cicatricosa (C.L. Koch, 1844)

Isoxya stuhlmanni (Bösenberg \& Lenz, 1885)

Larinia sp. imm.

Neoscona angulatula (Schenkel, 1937)

Neoscona quincasea Roberts, 1983

Neoscona subfusca (C.L. Koch, 1837)

Pararaneus spectator (Karsch, 1886)

Prasonica seriata Simon, 1895

Singa sp. imm.

CLUBIONIDAE

Clubiona sp. 1

Clubiona sp. 2

\section{CORINNIDAE}

Apochinomma formicaeforme Pavesi, 1881

Cambalida dippenaarae Haddad, 2012 $\uparrow$

Copa flavoplumosa Simon, 1885

Copuetta magna Haddad, $2013 \dagger$

Merenius alberti Lessert, 1923

\section{CTENIDAE}

B

Ctenus gulosus Des Arts, 1912

CYATHOLIPIDAE

Isicabu sp.

\section{CYRTAUCHENIIDAE}

Ancylotrypa brevipalpis (Hewitt, 1916)

Ancylotrypa nuda (Hewitt, 1916)

Homostola vulpecula Simon, 1892

DEINOPIDAE

Menneus camelus Pocock, 1902 imm.

\section{DICTYNIDAE}

Dictyna sp.

Mashimo sp.

Mizaga sp.

\section{DIPLURIDAE}

Allothele teretis Tucker, 1920

\section{ERESIDAE}

Dresserus colsoni Tucker, 1920 
APPPENDIX 1 (Continues...): Checklist of the arachnids of the Ophathe Game Reserve in KwaZulu-Natal, South Africa, with sampling methods in each habitat indicated.

Cheiracanthium vansoni Lawrence, 1936

Cheiramiona filipes (Simon, 1898)

Cheiramiona paradisus Lotz, 2002

GNAPHOSIDAE

Amusia cataracta Tucker, 1923

Aneplasa sp. 1

Aneplasa sp. 2

Aphantaulax inornata Tucker, 1923

Asemesthes decoratus Purcell, 1908

Camillina cordifera (Tullgren, 1910)

Camillina maun Platnick \& Murphy, 1987

Drassodes bechuanicus Tucker, 1923

Drassodes splendens Tucker, 1923

Echeminae sp. indet.

Ibala arcus (Tucker, 1923)

Micaria sp.

Nomisia tubula (Tucker, 1923)

Setaphis sp.

Trephopoda parvipalpa (Tucker, 1923)

Xerophaeus maritimus Lawrence, 1938

Xerophaeus sp. 2

Zelotes scrutatus (O.P.-Cambridge, 1872)

Zelotes tuckeri Roewer, 1951

Zelotes sp. 3 indet.

Zelotes sp. 4 indet.

HAHNIIDAE

Hahnia clathrata Simon, 1898

Hahnia tabulicola Simon, 1898

HERSILIIDAE

Hersilia sericea Pocock, 1898

\section{IDIOPIDAE}

Ctenolophus spiricola (Purcell, 1903)

Segregara monticola (Hewitt, 1916)

Segregara pectinipalpis (Purcell, 1903)

LINYPHIIDAE

Metaleptyphantes perexiguus (Simon \& Fage, 1922)

Pelecopsis sp.

LYCOSIDAE

Evippomma squamulatum (Simon, 1898)

Hippasa australis Lawrence, 1927

Lycosinae sp. 1

Lycosinae sp. 2

Lycosinae sp. 3

Minicosa neptuna Alderweireldt \& Jocqué, 2007

Pardosa crassipalpis Purcell, 1903

Pardosa sp. 2

Trabea sp.

Trochosa sp.?

MITURGIDAE

Parapostenus sp.

MYSMENIDAE

Isela okuncana Griswold, 1985

Mysmenidae sp. 1 indet.

L

L

A

L

N

A

A, L

A,L,N

NEMESIIDAE

Spiroctenus punctatus Hewitt, 1916

NEPHILIDAE

Nephilingis cruentata (Fabricius, 1775)

OECOBIIDAE

Oecobius navus Blackwall, 1859
$A, P$

$B$

L

$\mathrm{P}, \mathrm{W}$

N,P

$A, L, P$

$L, N$

$A, L, P$

A,P

P

$\mathrm{P}$

$L, P$

A,L,P

$\mathrm{B}, \mathrm{N}, \mathrm{P}$

B

A

$\mathrm{P}$

L,P

$L, P$

L

L

$A, N, P$

$P$

$A, L, P \quad A, P$

$P$

A, L,N,P,W

$A, L, P$

$A, N, P$

$L, P$

$A, P$

$A, L, P$

$A, P$

$P$

\section{OONOPIDAE}

Australoonops haddadi Platnick \& Dupérré, 2010† 
APPPENDIX 1 (Continues...): Checklist of the arachnids of the Ophathe Game Reserve in KwaZulu-Natal, South Africa, with sampling methods in each habitat indicated.

\begin{tabular}{llllll}
\hline Species & Ad hoc & MG & OR & OS
\end{tabular}

Gamasomorphinae sp. indet.

L

Opopaea speciosa (Lawrence, 1952)

\section{ORSOLOBIDAE}

Afrilobus sp.†

OXYOPIDAE

Hamataliwa sp.

L,P
A
$B, L, N, S$
B
B

Oxyopes jacksoni Lessert, 1915

Oxyopes pallidecoloratus Strand, 1906

Oxyopes sp. 3

A

Oxyopes sp. 4

Oxyopes sp. 5

Oxyopes sp. 6

Peucetia sp. imm.

PALPIMANIDAE

Palpimanus pseudarmatus Lawrence, 1952

Palpimanus sp. 2

PHILODROMIDAE

Gephyrota sp. imm.

Philodromus sp.

Philodromidae sp. indet.

Thanatus sp. imm.

Tibellus sp. imm.

PHOLCIDAE

Quamtana bonamanzi Huber, 2003

Smeringopus natalensis Lawrence, 1947

PHRUROLITHIDAE

Hortipes merwei Bosselaers \& Jocqué, 2000

Orthobula radiata Simon, 1897

PHYXELIDIDAE

Xevioso amica Griswold, 1990

\section{PISAURIDAE}

Afropisaura sp. imm.

Chiasmopes lineatus (Pocock, 1898)

Euprosthenops proximus Lessert, 1916

PRODIDOMIDAE

Theuma zuluensis Lawrence, 1947

Afromarengo bimaculata (Peckham \& Peckham, 1903)

Belippo meridionalis Wesołowska \& Haddad, 2013†

Bianor eximius Wesołowska \& Haddad, 2009

Colaxes benjamini Wesołowska \& Haddad, 2013†

Cyrba sp. imm.

Evarcha dotata (Peckham \& Peckham, 1903)

Evarcha prosimilis Wesołowska \& Cumming, 2008

Festucula haddadi Azarkina \& Foord, 2014

Habrocestum africanum Wesołowska \& Haddad, 2009

Heliophanus debilis Simon, 1901

Heliophanus demonstrativus Wesołowska, 1986

Heliophanus hastatus Wesołowska, 1986

Heliophanus pistaciae Wesołowska, 2003

Heliophanus trepidus Simon, 1910

Hispo inermis (Caporiacco, 1947)

Hyllus argyrotoxus Simon, 1902

Icius nigricaudus Wesołowska \& Haddad, 2009

Langelurillus sp.

A,L,P

$\mathrm{S}$

$A, B, L, P$

Massagris natalensis Wesołowska \& Haddad, 2009†

Mexcala elegans Peckham \& Peckham, 1903

P

Myrmarachne ichneumon (Simon, 1885)

Myrmarachne lulengana Roewer, 1965

\begin{tabular}{cccc} 
L & P & A & L \\
A & B & B & A, B \\
B & B & A,B,P & A \\
\hline
\end{tabular}


APPPENDIX 1 (Continues...): Checklist of the arachnids of the Ophathe Game Reserve in KwaZulu-Natal, South Africa, with sampling methods in each habitat indicated.

Species

MG

OR

OR

Natta horizontalis Karsch, 1879

Nigorella hirsuta Wesołowska, 2009

Pachyballus castaneus Simon, 1900 ?

Pellenes bulawayoensis Wesołowska, 1999

Pellenes pulcher Wesołowska, 1999

Phintella aequipes (Peckham \& Peckham, 1903)

$\mathrm{L}$

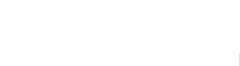

L

B

Phlegra bresnieri (Lucas, 1846)

Phlegra imperiosa Peckham \& Peckham, 1903

Phlegra sp. $3 \mathrm{imm}$.

Pignus simoni (Peckham \& Peckham, 1903)

Portia schultzi Karsch, 1878

Pseudicius dentatus Wesołowska \& Haddad, 2013†

Rhene sp. imm.

Stenaelurillus sp. 1

Stenaelurillus sp. $2 \mathrm{imm}$.

Tanzania parvulus Wesołowska, Azarkina \& Russell-Smith, 2014

Thyene inflata (Gerstaecker, 1873)

Thyene natalii Peckham \& Peckham, 1903

Thyene ogdeni Peckham \& Peckham, 1903

Thyene pulchra Peckham \& Peckham, 1903

Thyene semiargentea (Simon, 1884)? imm.

Thyenula fidelis Wesołowska \& Haddad, 2009

Thyenula virgulata Wesołowska, Azarkina \& Russell-Smith, 2014†

Tusitala barbata Peckham \& Peckham, 1902

Veissella durbani (Peckham \& Peckham, 1903) imm.

Ureta quadrispinosa (Lawrence, 1938)

\section{SCYTODIDAE}

Scytodes caffra Purcell, 1905

Scytodes maritima Lawrence, 1938

Scytodes rubra Lawrence, 1937

Scytodes sp. 4

SEGESTRIIDAE

Ariadna corticola Lawrence, 1952

SELENOPIDAE

Anyphops pococki (Lawrence, 1940)

Selenops sp. imm.

SPARASSIDAE

Olios sjostedti Lessert, 1921

Olios sp. 2

Olios sp. $3 \mathrm{imm}$

Palystes superciliosus L. Koch, 1875

Panaretella sp.

\section{TETRAGNATHIDAE}

Leucauge sp. imm.

Tetragnatha sp. imm.

\section{THERAPHOSIDAE}

Brachionopus robustus Pocock, 1897

Harpactira sp. imm.

THERIDIIDAE

Achaearaneae sp.

Anelosimus sp. 1

Anelosimus sp. 2

Anelosimus sp. 3

Anelosimus sp. 4

Argyrodes stridulator Lawrence, 1937

Chorizopella sp.

Coleosoma sp. 1

Coleosoma sp. 2

Dipoena sp.

Enoplognatha sp.?

L

A,L

OS

B 
APPPENDIX 1 (Continues...): Checklist of the arachnids of the Ophathe Game Reserve in KwaZulu-Natal, South Africa, with sampling methods in each habitat indicated.

\begin{tabular}{|c|c|c|}
\hline Species & Ad hoc & MG \\
\hline Episinus sp. imm. & B & \\
\hline Euryopis sp. 1 & & $\mathrm{~L}$ \\
\hline Euryopis sp. 2 & & L \\
\hline Euryopis sp. 3 & & L \\
\hline \multicolumn{3}{|l|}{ Euryopis sp. 4} \\
\hline Euryopis sp. $5 \mathrm{imm}$. & & $\mathrm{L}$ \\
\hline Latrodectus geometricus C.L. Koch, 1841 & B & \\
\hline Phoroncidia sp. 1 & & B \\
\hline Phoroncidia sp. 2 & & B \\
\hline \multicolumn{3}{|c|}{ Steatoda erigoniformis (O.P.-Cambridge, 1872) } \\
\hline \multicolumn{3}{|l|}{ Theridiidae indet. sp. 1} \\
\hline \multicolumn{3}{|l|}{ Theridiidae indet. sp. 2} \\
\hline \multicolumn{3}{|l|}{ Theridiidae indet. sp. 3} \\
\hline \multicolumn{3}{|l|}{ Theridion sp. 1} \\
\hline \multicolumn{3}{|l|}{ Theridion sp. 2} \\
\hline Theridion sp. 3 & & B \\
\hline Theridion sp. 4 & & \\
\hline
\end{tabular}

MG OR

OR OS

os

RM

Euryopis sp. 1

L

L

Theridion sp. 5

Theridula sp.

Thymoites sp.

Tidarren $\mathrm{sp}$.

\section{THOMISIDAE}

Ansiae tuckeri (Lessert, 1919)

Diaea sp. 1

Diaea sp. 2

Heriaeus crassispinus Lawrence, $1942 \mathrm{imm}$.

Misumenops rubrodecoratus Millot, 1941

Monaeses quadrituberculatus Lawrence, 1927

A

B

Mystaria savannensis Lewis \& Dippenaar-Schoeman, 2014†

Oxytate sp. imm.

Parasmodix quadrituberculata Jézéquel, 1966

Pherecydes nicolaasi Dippenaar-Schoeman, $1980 \mathrm{imm}$.

Pherecydes zebra Lawrence, 1927

Runcinia flavida (Simon, 1881)

Runcinia sp. $2 \mathrm{imm}$.

Simorcus cotti Lessert, 1936. imm.

Smodicinus coroniger Simon, 1895

Stiphropus affinis Lessert, 1923

Stiphropus intermedius Millot, 1941

Sylligma ndumi Lewis \& Dippenaar-Schoeman, 2011†

Synema decens (Karsch, 1878)

Synema nigrotibiale Lessert, 1919

Synema sp. 3

Thomisidae sp. 1 indet.

Thomisidae sp. 2 indet.

Thomisops pupa Karsch, 1879

Thomisops senegalensis Millot, 1941

Thomisus daradioides Simon, 1890

Thomisus sp. $2 \mathrm{imm}$.

Thomisus sp. $3 \mathrm{imm}$.

Thomisus sp. $4 \mathrm{imm}$.

Tmarus africanus Lessert, 1919

Tmarus cameliformis Millot, 1942

Tmarus comellinii Garcia-Neto, 1989

Tmarus natalensis Lessert, 1919

Tmarus planetarius Simon, 1903

Xysticus lucifugus Lawrence, 1937

Xysticus urbensis Lawrence, 1952

\section{TRACHELIDAE}

Fuchiba aquilonia Haddad \& Lyle, 2008 
APPPENDIX 1 (Continues...): Checklist of the arachnids of the Ophathe Game Reserve in KwaZulu-Natal, South Africa, with sampling methods in each habitat indicated.

\begin{tabular}{llllll}
\hline Species & Ad hoc & MG & OR & OS & RM
\end{tabular}

\section{TROCHANTERIIDAE}

Platyoides walteri (Karsch, 1886)

Platyoides sp. $2 \dagger$

B

\section{ULOBORIDAE}

Miagrammopes sp. imm

Uloborus sp.

ZODARIIDAE

Caesetius bevisi (Hewitt, 1916)

Cicynethus sp. imm

Cydrela sp. imm.

Diores sp. $\dagger$

P

Microdiores sp. $\dagger$

Psammorygmasp.

Ranops sp. imm.

Zodariinae sp. indet.

ORDER: OPILIONES (HARVESTMEN)

\section{BIANTIDAE}

Metabiantes kosibaiensis Kauri, 1961

A

Metabiantes litoralis Kauri, 1961

$A, L$

TRIAENONYCHIDAE

Monomontia corticola Lawrence, 1938

$A, L$

ORDER: PSEUDOSCORPIONES (PSEUDOSCORPIONS)

\section{ATEMNIDAE}

Catatemnus $\mathrm{sp}$

CHELIFERIDAE

Aperittochelifer $\mathrm{sp}$.

\section{GEOGARYPIDAE}

Geogarypus sp.

OLPIIDAE

Horus sp.

ORDER: SCORPIONES (SCORPIONS)

\section{BUTHIDAE}

Uroplectes formosus formosus Pocock, 1890

Uroplectes triangulifer marshalli Hewitt, 1918

A

A
A
Cheloctonus jonesii Pocock, 1892

Hadogenes zuluanus Lawrence, 1937

Opisthacanthus asper (Peters, 1861)

\section{ORDER: SOLIFUGAE (SUN SPIDERS)}

SOLPUGIDAE

Solpugidae sp. 1 indet.

labitats: MG, montane grassland; OR, Ombesanoni River bed; OS, overgrazed savanna; RM, rocky mountainside.

Sampling method: A, active searching; B, beating; L, litter sifting; N, night collecting; P, pitfall trapping; S, sweep-netting; W, Winkler traps.

$\dagger$, new species. 